$$
\begin{gathered}
\text { Espacio y Desarrollo } \mathrm{N}^{\circ} 34,2019 \text {, pp. 117-137 (ISSN 1016-9148) } \\
\text { https://doi.org/10.18800/espacioydesarrollo.201902.005 }
\end{gathered}
$$

\title{
EL TURISMO EN ESPACIO RURAL: UN ANÁLISIS DE LA POTENCIALIDAD DEL distrito de Lachaqui, provincia de Canta de la Región de Lima, Perú
}

\author{
Edwin N. Gabriel Campos \\ https://orcid.org/0000-0003-0245-0040 \\ Universidad Nacional Mayor de San Marcos \\ egabrielc@unmsm.edu.pe
}

Fecha de recepción 03/02/2020

Fecha de aceptación 26/05/2020

\section{RESUMen}

El estudio se encuentra enfocado en el análisis del potencial turístico del espacio rural del distrito de Lachaqui, el cual permitió enmarcar el objetivo del trabajo que, a la vez, ha podido determinar y encaminar la investigación. La situación del área de estudio se vincula a una problemática común en muchos espacios rurales del país, pues presentan recursos turísticos sin serlos oficialmente, debido a que no se encuentran registrados en el inventario del Ministerio de Comercio Exterior y Turismo. Además, la situación en la que se encuentra el sistema turístico, con base en los elementos que lo conforman, han permitido analizar el potencial turístico del área de estudio mediante un modelo basado en una matriz que permite determinar la potencialidad turística. El estudio utiliza un método de carácter mixto, pues ha logrado combinar métodos cualitativos y cuantitativos. El resultado más significativo ha sido que el espacio rural de Lachaqui presenta una mediana o regular potencialidad, y ello se explica por la situación actual de cada componente del sistema turístico dentro del área de estudio. Por ello, la planificación del turismo con un enfoque territorial, donde se conjugan los procesos sociales y naturales con empoderamiento de la dinámica comunal, y la prevalencia de la sostenibilidad sobre la rentabilidad, será relevante para elevar la potencialidad del espacio rural de Lachaqui.

Palabras clave: espacio rural, Lachaqui, potencial turístico, sistema turístico.

Tourism in Rural Areas: An Analysis of the Potential in the Lachaqui District, Canta Province of Lima, Lima Region, Peru

\section{Abstract}

The study focuses on the analysis of the tourist potential of the rural area of the Lachaqui district, this allowed to frame the objective of the work that at the same time has been able to determine and direct the research. The situation of the study area is linked to a common problem in many rural areas of the country, since they present tourist resources without being officially, 
because they are not registered in the inventory of the Ministry of Foreign Trade and Tourism. In addition, the situation in which is the tourism system in base the elements that compose it, has made it possible to analyze the tourism potential of the study area using a model based on a matrix that allows determining the tourism potential. The study uses a mixed method, since it has managed to combine qualitative and quantitative methods. The most significant result has been that the rural area of Lachaqui has a medium or regular potential, and this is explained by the current situation of each component of the tourist system within the study area. For this reason, tourism planning with a territorial approach, where social and natural processes are combined with the empowerment of community dynamics and the prevalence of sustainability over profitability, will be relevant to increase the potential of the rural area of Lachaqui. Keywords: rural area, Lachaqui, tourism potential, tourism system.

\section{INTRODUCCIÓN}

El abordaje del presente estudio se ha realizado desde la perspectiva del espacio rural como escenario para el turismo, ello bajo la mirada de la sostenibilidad en el distrito de Lachaqui que, por las características geográficas de su territorio, observa al turismo como una actividad alterna que podría servir de sustento económico a los locales.

En principio, el desenvolvimiento del turismo en determinado espacio obedece a una serie de factores que condicionan o determinan el desarrollo de esta actividad; sin embargo, comprender el espacio ha sido un tema de debates en las distintas disciplinas científicas. Al respecto, Ramírez y López (2015) sostienen que el espacio como concepto se caracteriza por su concepción polisémica, ya que su utilización involucra a distintas disciplinas científicas, como la física, economía, antropología, geografía, entre otros. Pese a ello, es dentro de las ciencias sociales que ha podido encontrar un nicho para su debate y discusión (Delgado, 2001) y que ha permitido que la geografía se repotencie como aquella disciplina del espacio, o a lo que se denomina «espacio geográfico", definido como aquel espacio constituido por fijos y flujos (Santos, 1996). Bajo esta mirada, el espacio geográfico se caracteriza por su constante transformación como producto de las constantes interrelaciones entre la sociedad y su entorno natural. Es por esta razón que se concibe al espacio como una constante construcción social (Lefebvre, 1974; Harvey, 2007; Santos, 1996; Rojas, 2005; Ramírez y López, 2015) donde la acción constante y el trabajo del hombre ha jugado y juega un rol transformador, y es en ese escenario donde el turismo logra articular los elementos del espacio geográfico logrando transformarlo. En la actualidad existe una constante discusión acerca de la tipificación o categorización del espacio, pues dependerá del objetivo del sujeto; sin embargo, desde una perspectiva de la planificación o gestión del territorio, se estila diferenciar el espacio urbano del espacio rural. 


\subsection{Espacio rural y espacio turístico}

La conceptualización y definición del espacio rural es compleja ya que se encuentra estrechamente relacionada a realidades regionales y locales donde las normativas administrativas dentro de determinado territorio; configuran una serie de indicadores para determinarlo como área rural, tal como el número de población, actividades de producción, entre otros. Sin embargo, el espacio rural se encuentra configurado por lo rural, término definido de forma general como aspecto perteneciente o relativo a la vida del campo y a sus labores (RAE, 2018). Esta vida de campo dependerá de cada realidad en cada país o región, ya que las cualidades que definen como rural en los países de Europa occidental no concordaron en países de Latinoamérica o Asia oriental. Ante ello, Calame (2010) define al espacio rural en contraste con los espacios urbanos; y García, Tullas y Valdovinos (1995) sostienen que «Es evidente que el espacio rural no puede entenderse como una realidad aislada y matemáticamente definida, ya que debemos considerarlo, históricamente, en el contexto de una polarización territorial entre los núcleos urbanos y el resto del territorio» (p. 41).

Hasta hace algún tiempo, era tácita la diferencia entre un espacio urbano y rural; sin embargo, debido a una serie de situaciones en las cuales el campo viene sufriendo procesos de urbanización, y algunos centros urbanos también sufren procesos de ruralismo - como la agricultura urbana-, existe en estos tiempos procesos transformadores del espacio rural o como lo denominan muchos expertos, la nueva ruralidad (García, Tullas y Valdovinos, 1995). Sin embargo, las actividades propias dentro de estos espacios no solo se limitan a la agropecuario, sino que a la vez se desarrollan otras actividades económicas como la tala, pesca, minería, entre otros. Es en esta nueva ruralidad surge el turismo, el cual fortalece la idea de que el espacio rural no solo está compuesto por espacios de producción sino también de consumo (Posada, 1999). Por la singularidad de su praxis, se le categoriza como turismo rural a la actividad que se desarrolla dentro de este espacio, que integrado con los elementos del sistema turístico como la planta turística, infraestructura, gobernanza, entre otros, configuraría el espacio turístico de este espacio rural, ya que todo espacio rural no es turístico.

Cabe resaltar que el espacio turístico, al igual que el espacio geográfico, es una construcción social producto de la interacción por consumo del turista con los elementos que definen al mismo espacio, como son los atractivos, infraestructura, etc. No obstante, se debe resaltar que el espacio turístico tiene su soporte físico en el espacio geográfico donde el medio físico es su principal característica; además de ello, dentro de este espacio existe un grupo de individuos que durante el histórico ha estructurado un tejido social mediante una serie de interacciones, que ha generado un empoderamiento sobre su espacio. Este concepto se encuentra focalizado en el territorio. Cabe resaltar que el término de territorio es más amplio que el de espacio físico, porque combina el medio físico natural y el espacio empoderado por un grupo social (Vargas, 2012). 
El turismo es una variable social en el espacio, y el empoderamiento territorial por parte de los actores turísticos, como empresas de servicios turísticos, grupos de interés empresarial, grupos de interés sindical, entre otros (Merinero y Zamora, 2009). Algunas veces, genera diversos conflictos que pueden tener como causa a esta actividad, es por ello que, en la planificación del turismo, no solo debe prevalecer la satisfacción del turista o la visión económica de la actividad: la mirada del espacio turístico como un territorio intervenido por el turismo ampliarían la centralidad de las propuestas.

\subsection{Planificación del espacio turístico}

El espacio turístico es un espacio físico concreto y, por consiguiente, la planificación del espacio turístico corresponde al proceso de planificación física, que se define como «una técnica que pertenece a las categorías fácticas del conocimiento científico (Boullón 2006). Su finalidad es el ordenamiento de las acciones del hombre sobre el territorio y se ocupa de resolver armónicamente la construcción de todo tipo de cosas, así como de anticipar el efecto de la explotación de los recursos naturales» (p. 193). De este concepto se desprende la necesidad de que el territorio, para una mitigación de los impactos de las actividades humanas —entre ellas el turismo-, debe seguir políticas de ordenamiento, por ello el turismo no es ajeno a esta realidad, y en la actualidad, en diversas literaturas se difunde el concepto de ordenamiento turístico, enfocado a una mejor organización del turismo sobre el territorio.

El primer paso —o uno de los primeros pasos para dar inicio a este proceso de ordenamiento-, bajo el contexto de un proceso de planificación del espacio turístico, es identificar los elementos con que cuenta el territorio que le brindará el carácter turístico, esto refiere a los rasgos que lo constituyen, que son los recursos turísticos, infraestructura, planta turística, superestructura y la misma comunidad local, componentes que constituyen el sistema turístico (Boullón, 2006; Ricaurte, 2009; Zimmer y Grassman, 1996; Pariente, Chávez y Reynel, 2016; Mora, 2010). En la gestión local, este primer paso forma parte del inventario de recursos turísticos que en muchos trabajos como el de Bassan y Cravero (2013) se pone de manifiesto. El procedimiento para la identificación e inventario de los recursos turísticos de determinado espacio, se encuentra establecido y normado por el Mincetur (2012), procedimiento que, cada cierto, tiempo se reinventa, ya que los elementos que conforman el sistema turístico son dinámicos y cambiantes.

Existe una serie de propuestas en la determinación de los elementos del sistema turístico, sin embargo, la mirada de Molina (citado por Ricaurte, 2009) considera los elementos que participan en la planificación turística del territorio. Tales son la superestructura, demanda, comunidad receptora, atractivos turísticos, planta turística e infraestructura. Los elementos mencionados configuran al espacio turístico y la integridad e interrelación entre estos determinan el sistema turístico de un territorio. 
Sin embargo, para fines del presente estudio, se plantea una estructuración de tales componentes de acuerdo con la realidad del espacio de estudio, y se configura tal cual la figura siguiente.

Figura 1. Componentes del sistema turístico del espacio rural de Lachaqui para el análisis de su potencialidad

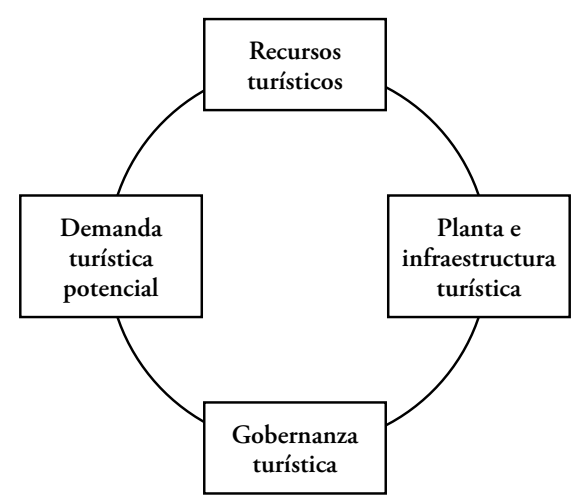

Fuente: Adaptado de Molina (citado por Ricaurte, 2009).

La planificación del espacio turístico es una herramienta de gestión territorial trascendental para el alcance de la sostenibilidad del turismo en determinado espacio. Este proceso presenta una variada estructuración dependiendo de los diversos enfoques o miradas cuya capacidad se irá adaptando en forma y fondo de acuerdo a la realidad cambiante. Para un adecuado proceso de planificación del turismo debe tenerse la certeza de que el territorio o espacio objeto presenta el potencial turístico adecuado para llegar a satisfacer las necesidades vinculantes; de no ser así, el proceso de planificación en un espacio turístico sin potencial para ello caería una mera actividad sin direccionalidad.

El potencial territorial para el turismo de determinado espacio se encuentra relacionado a las capacidades que cuenta cada uno de los elementos del territorio que permitan la dinámica del turismo como actividad que no solo permita el flujo de turistas y/o visitantes sobre el territorio, sino que además logre satisfacer las necesidades de ellos sin vulnerar su estadía, permanencia y desplazamiento. Al respecto, se conceptualiza como la «capacidad o aptitud de éste para desarrollar actividades dada las cualidades que se posee en sus diferentes dimensiones (ambiental, sociocultural, económica, políticoinstitucional), donde dichas cualidades identificadas permitirán la priorización de uso del territorio" (Mikery y Pérez, 2014). La determinación del potencial turístico debe ser acorde a la realidad geográfica de un territorio sin minimizar ni maximizar caracteres de los elementos vinculantes al fenómeno turístico, ya que «una visión errónea del potencial turístico local puede provocar un sobredimensionamiento de los proyectos, 
con efectos negativos sobre el medio ambiente, la cultura y la actividad económica del territorio» (Zimmer y Grassmann, 1996).

Para determinar el nivel o grado de potencialidad que posee un territorio para el desarrollo del turismo, se han planteado una serie de metodologías, que van desde una evaluación cualitativa de los recursos turísticos y su estado de conservación, hasta métodos utilizando el análisis multicriterio espacial con ayuda del SIG (Sistema de Información Geográfica) (Mikery y Perez,2014). Sin embargo, cada modelo metódico obedece a ciertos caracteres espaciales y temporales, ello por la misma dinámica que caracteriza al territorio. Depende, además, de algunos criterios, como el enfoque del turismo o su tipología (Díaz, Nava, Gallardo, García y Fajersson, 2008) para el caso del ecoturismo (Soria, 2014) con la propuesta del método mexicano Fuzzy-Sectur, o con la matriz de evaluación del potencial turístico (Sandoval, 2006).

Covarrubias (2014) sostiene que «el potencial turístico lo determina la forma en que la oferta de productos y servicios turísticos de una localidad se adapta para satisfacer las necesidades actuales de esparcimiento y recreación de los turistas nacionales e internacionales» (p. 23). De ello, se infiere que es trascendental realizar una caracterización previa del espacio geográfico del área de estudio, con la finalidad de identificar si dicho espacio contiene los elementos suficientes que determinen estructural y funcionalmente las matices que direccionen la praxis del desarrollo del turismo dentro del espacio rural del área de estudio.

En esta misma línea, la investigación ha pretendido analizar la potencialidad que presenta el espacio rural del distrito de Lachaqui para el desarrollo del turismo dentro de su territorio, ello forma parte del objetivo del estudio, que ha permitido a la vez guiar las actividades de la investigación.

\section{Materiales Y MÉTOdo}

\subsection{Metodología}

Por las características que presenta la presente investigación, se ha seguido un método con enfoque mixto, multimetódico, de enfoque total o multimodal (Naupas, Mejía, Novoa y Villagómez, 2014), ello debido a que en el estudio se utilizó una serie de métodos cualitativos y cuantitativos, como es el caso de la aplicación de entrevistas, observación y cuestionario como instrumentos y técnicas de recojo de información, además se valió de herramientas cartográficas para el alcance de los objetivos específicos, así como se utilizó el programa estadístico SPSS para el tratamiento de los resultados del cuestionario. Cabe resaltar que el objeto de estudio presenta dimensiones espaciales, lo que ahonda más la necesidad del uso de este enfoque para su abordaje y comprensión. 
La investigación se desarrolló bajo el diseño no experimental —enfoque cuantitativo-, etnográfico y fenomenológico (Hernández, Fernández y Baptista, 2014), siendo diseños en la que está comprendido el estudio. Es etnográfico debido a que, en el proceso del trabajo de campo, ha sido necesario establecer entrevistas y observaciones a informantes claves. Es, además, fenomenológico debido a que la variable de estudio corresponde a un hecho social de determinado espacio que es cambiante a través del tiempo, en este caso la potencialidad del turismo, ya que los resultados que arroje el estudio podrán ser utilizados para la toma de decisiones en el municipio en un inmediato tiempo, pero si el municipio desea tomar estos resultados en unos cinco años o más, posiblemente la información no será trascendental por la volubilidad del hecho social.

Otro aspecto relevante en la investigación es que, para determinar la potencialidad del espacio rural, se ha utilizado y adaptado la matriz de potencialidad de Sandoval (2006), tal cual se muestra en la Tabla 1, ello por contar con indicadores que permiten una mayor facilidad en la evaluación espacial.

Tabla 1. Matriz de potencialidad turística del espacio rural

\begin{tabular}{|c|c|c|c|}
\hline \multirow{2}{*}{ Indicadores de potencialidad } & \multicolumn{3}{|c|}{ Valor numérico } \\
\hline & 3 & 2 & 1 \\
\hline Cercanía a centros urbanos importantes & Cerca & $\begin{array}{l}\text { Relativamente } \\
\text { cerca }\end{array}$ & Lejos \\
\hline Características del trayecto hacía el área & Cómodo & Fácil & Peligroso \\
\hline $\begin{array}{l}\text { Posibilidades de desarrollo de actividades de } \\
\text { turismo rural comunitario }\end{array}$ & Varias & Algunas & Pocas \\
\hline $\begin{array}{l}\text { Presencia de atractivos para el turismo rural } \\
\text { comunitario }\end{array}$ & Fuerte & Moderado & Débil \\
\hline Posibilidad de observar paisaje rural & Garantizado & Frecuente & $\begin{array}{l}\text { Depende de la } \\
\text { época }\end{array}$ \\
\hline Características de interés turístico & Varias & Más de una & $\begin{array}{l}\text { Depende de la } \\
\text { época }\end{array}$ \\
\hline Lugares de interés cultural & Muchos lugares & Algunos lugares & Pocos lugares \\
\hline Las características intrínsecas del área son: & Únicas & Algo diferentes & $\begin{array}{l}\text { Similares a } \\
\text { otras zonas }\end{array}$ \\
\hline $\begin{array}{l}\text { Potencialidad escénica de los alrededores del } \\
\text { área }\end{array}$ & $\begin{array}{l}\text { De una gran } \\
\text { belleza paisajística }\end{array}$ & $\begin{array}{l}\text { Un verdadero } \\
\text { atractivo }\end{array}$ & $\begin{array}{l}\text { De poco } \\
\text { interés }\end{array}$ \\
\hline $\begin{array}{l}\text { Potencial para integrar el área a circuitos de } \\
\text { interés turístico }\end{array}$ & Gran potencial & $\begin{array}{l}\text { Potencial } \\
\text { moderado }\end{array}$ & Poco potencial \\
\hline
\end{tabular}

Suma de evaluación de potencialidad

Fuente: Adaptado de Sandoval, 2006. 
En primer lugar, se ha utilizado la matriz a nivel de cada recurso turístico, y, al final, a nivel de la totalidad del espacio rural de Lachaqui, lo que ha permitido analizar la potencialidad turística en el área de estudio. Cabe resaltar que la valoración de cada punto obedece a un análisis de la situación de cada componente del sistema turístico dentro del espacio rural, como son los recursos turísticos, la planta e infraestructura turística, la gobernanza y la demanda turística.

Luego de valorar cada aspecto, de acuerdo al valor obtenido, se determina el nivel de potencialidad de acuerdo a la Tabla 2:

Tabla 2. Potencialidad del turismo de acuerdo con la escala de valoración determinada

\begin{tabular}{cc}
\hline Escala de valoración numérica & Categorías de potencialidad \\
\hline $30-25$ & Alto potencial (AP) \\
$24-15$ & Mediano potencial (MP) \\
$14-10$ & Bajo potencial (BP) \\
\hline
\end{tabular}

Fuente: Sandoval, 2006.

En esta tabla, "Alta potencialidad» se refiere a un espacio integrado turísticamente, con recursos, paisaje, conectividad y accesibilidad en buen estado para las visitas, además de una amplia variedad de servicios en alimentación y alojamiento. «Mediana potencialidad", por su parte, se traduciría como un espacio turístico con recursos, paisaje, conectividad y accesibilidad en buen estado, pero con algunas limitaciones o deficiencias en alguno de estos componentes del paisaje y espacio rural, además de limitados servicios en alimentación y alojamiento. Finalmente, «Bajo potencial» estaría relacionado a un espacio turístico reconocido como tal, pero con altas deficiencias en el estado de sus recursos, así como en el paisaje, la conectividad y accesibilidad, además de limitados servicios en alimentación y alojamiento, que, a la vez, funcionarían temporalmente.

\section{1. Área de estudio}

El espacio rural de Lachaqui forma parte del distrito del mismo nombre, el cual, a su vez, pertenece a la provincia de Canta, en la región Lima Provincias. Cuenta con una superficie de $138 \mathrm{~km}^{2}$, limita al norte con el distrito de Canta y San Buenaventura, también limita por el sur con el distrito de Arahuay, al este con el distrito de Laraos de la provincia de Huarochirí, y al oeste con los distritos de Huamantanga y Santa Rosa de Quives. Se ubica, a la vez, en la margen izquierda del río Chillón y es cruzado por uno de sus afluentes: el río Quisquichaca, denominado también «Arahuay». El centro urbano y capital del distrito se ubica a unos $3625 \mathrm{~m} \mathrm{~s}$. n. m. La afluencia del río Quisquichaca en el río Chillón ocurre por su margen izquierdo en la localidad de Santa Rosa de Quives. 
Figura 2. Mapa de ubicación del distrito de Lachaqui
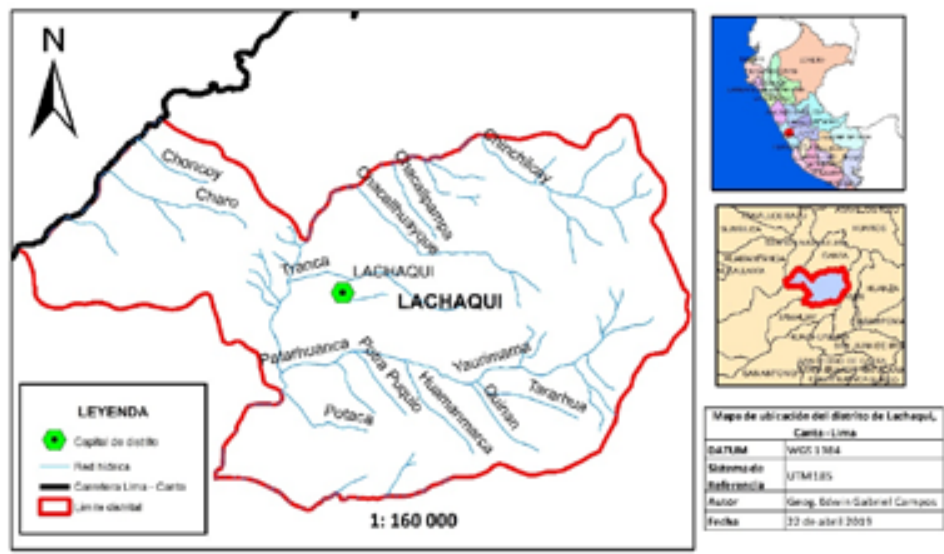

Elaboración propia, 2019.

De acuerdo con el historiador Frank Huamaní, el nombre del distrito Lachaqui aún no se ha determinado históricamente cuál podría ser su real significado, en las crónicas se encuentra que se llamaba como «Lachaque», o «Mar chaque», ello se puede asociar al quechua «llachaqui» que significa "pie descalzo», o «callacharqui» que significa «el que come carne seca o charqui» que coincide con un dato colonial de María Rostoworowski y León, en el cual resalta que este espacio destaca en la producción de la carne seca. En todo caso, ambas interpretaciones le dan una connotación andina a este espacio.

\section{Discusión de RESUltados}

\subsection{Los recursos turísticos de Lachaqui}

De acuerdo con el procedimiento de categorización de los recursos turísticos del Ministerio de Comercio Exterior y Turismo (Mincetur, 2012) del Perú, los recursos turísticos identificados se resumen en la Tabla 3. Cabe resaltar que corresponde a los que la Municipalidad Distrital de Lachaqui ha desarrollado en el informe de inventario de recursos turísticos del año 2018, pues no son los únicos elementos del espacio rural que podrían ser turísticos. Existen otros que no han sido categorizados, entre ellas diversas fiestas culturales locales que simbolizan la identidad de la comunidad local, como es la fiesta de las cruces, la fiesta del agua, entre otros; ello debido a que se ha considerado los elementos del paisaje rural con una adecuada conexión y accesibilidad al centro urbano del distrito, mediante carreteras afirmadas o caminos de herradura, Ahí se encuentran los servicios que podrían demandar los visitantes a este espacio, como alimentación y descanso. La conexión y accesibilidad son características claves para que un elemento del paisaje, como las cataratas, miradores, centros arqueológicos, entre 
otros; presenten un atractivo turístico, y es bajo ese enfoque que se ha identificado los siguientes recursos turísticos.

Tabla 3. Recursos turísticos del espacio rural de Lachaqui

\begin{tabular}{|c|c|c|c|c|c|}
\hline $\mathrm{N}^{\circ}$ & Nombre & Código & Categoría & Tipo & Subtipo \\
\hline 1 & $\begin{array}{l}\text { San José de Viscas de } \\
\text { Lachaqui }\end{array}$ & SJVL & $\begin{array}{l}\text { Manifestaciones } \\
\text { culturales }\end{array}$ & Pueblos & $\begin{array}{l}\text { Pueblos } \\
\text { históricos }\end{array}$ \\
\hline 2 & $\begin{array}{l}\text { Centro Arqueológico } \\
\text { Quekamarca de Lachaqui }\end{array}$ & CAQL & $\begin{array}{l}\text { Manifestaciones } \\
\text { culturales }\end{array}$ & $\begin{array}{l}\text { Sitios } \\
\text { arqueológicos }\end{array}$ & Edificaciones \\
\hline 3 & $\begin{array}{l}\text { Paisaje arqueológico } \\
\text { de Huanchosmarca de } \\
\text { Lachaqui }\end{array}$ & PAHL & $\begin{array}{l}\text { Manifestaciones } \\
\text { culturales }\end{array}$ & $\begin{array}{l}\text { Sitios } \\
\text { arqueológicos }\end{array}$ & Edificaciones \\
\hline 4 & $\begin{array}{l}\text { Puente de Piedra de } \\
\text { Viscas de Lachaqui }\end{array}$ & PPVL & $\begin{array}{l}\text { Manifestaciones } \\
\text { culturales }\end{array}$ & $\begin{array}{l}\text { Lugares } \\
\text { históricos }\end{array}$ & Puente \\
\hline 5 & $\begin{array}{l}\text { Pueblo Santiago } \\
\text { Luorcocha de Lachaqui }\end{array}$ & PSLL & $\begin{array}{l}\text { Manifestaciones } \\
\text { culturales }\end{array}$ & Pueblos & $\begin{array}{l}\text { Pueblos } \\
\text { históricos }\end{array}$ \\
\hline 6 & $\begin{array}{l}\text { Mirador del Cerro } \\
\text { Champacra de Lachaqui }\end{array}$ & MCChL & Sitios naturales & $\begin{array}{l}\text { Lugares } \\
\text { pintorescos }\end{array}$ & $\begin{array}{l}\text { Mirador } \\
\text { natural }\end{array}$ \\
\hline 7 & $\begin{array}{l}\text { Mirador del Cerro } \\
\text { Cullpe de Lachaqui }\end{array}$ & MCCL & Sitios naturales & $\begin{array}{l}\text { Lugares } \\
\text { pintorescos }\end{array}$ & $\begin{array}{l}\text { Mirador } \\
\text { natural }\end{array}$ \\
\hline 8 & $\begin{array}{l}\text { Bosque de Piedra de } \\
\text { Lachaqui }\end{array}$ & $\mathrm{BPL}$ & Sitios naturales & Montañas & $\begin{array}{l}\text { Bosque de } \\
\text { piedras }\end{array}$ \\
\hline 9 & $\begin{array}{l}\text { Rastro del Inca de } \\
\text { Lachaqui }\end{array}$ & RIL & Sitios naturales & $\begin{array}{l}\text { Lugares } \\
\text { pintorescos }\end{array}$ & $\begin{array}{l}\text { Caminos } \\
\text { pintorescos }\end{array}$ \\
\hline
\end{tabular}

Fuente: Informe de inventario de recursos turísticos de la Municipalidad Distrital de Lachaqui, 2018.

En la Tabla 3 se aprecian nueve recursos turísticos en el espacio rural de Lachaqui, dicha lista resume la importante potencialidad para estructurar el espacio turístico de dicha localidad. Es posible encontrar manifestaciones culturales como recursos predominantes, así como destacados sitios naturales para la experiencia del visitante. Cabe resaltar que la naturalidad de estos recursos identificados forma parte de procesos naturales y sociales totalmente desligados de alguna funcionalidad turística, pues los miradores a la cual se les ha identificado como recursos turísticos, son espacios de adoración y misticismo por la población local pues cada cierto tiempo se convierten en escenarios para la fiesta de las cruces como parte de la tradición local. Los centros arqueológicos, el pueblo de piedras de San José de Viscas y el puente de piedra, son espacios donde queda evidencia de la relación social de grupos humanos del pasado; el bosque de piedras y el rastro del inca, son muestras de formas geológicas resultado de la erosión constante de la lluvia y el viento, procesos naturales comunes en estos 
espacios. La direccionalidad al consumo turístico obedece a un contexto cada vez más emergente por generar espacios turísticos.

\subsection{Demanda turística potencial de Lachaqui}

De acuerdo con el cuestionario aplicado a una muestra aleatoria de cien individuos respecto al perfil de la demanda potencial que visitaría Lachaqui, los resultados se muestran resumidos en la Tabla 4.

Tabla 4. Perfil de la demanda turística potencial de Lachaqui

\begin{tabular}{|c|c|c|}
\hline Aspectos & Valor resaltante & Perfil del visitante potencial \\
\hline Edad & $54 \% 18$ a 25 años & \\
\hline Estado civil & $70 \%$ solteros & $\begin{array}{l}\text { Predominantemente } \\
\text { jóvenes, solteros }\end{array}$ \\
\hline Medio de transporte utilizado & $38 \%$ transporte público & universitarios, \\
\hline Medio de información utilizado & $38 \%$ internet, periódicos & dependientes y activos \\
\hline Ingresos económicos & $\begin{array}{l}44 \% \text { menos a los } 1000 \text { soles } \\
\text { mensuales }\end{array}$ & $\begin{array}{l}\text { laboralmente, con } \\
\text { ingresos mensuales }\end{array}$ \\
\hline Ocupación & $38 \%$ trabajadores dependientes & $\begin{array}{l}\text { utilizan el transporte } \\
\text { menores a }\end{array}$ \\
\hline Situación laboral & $90 \%$ activos laboralmente & público, la internet y \\
\hline Estudios realizados & $48 \%$ estudios universitarios & periódico, motivados \\
\hline Preferencias & $86 \%$ naturaleza & $\begin{array}{l}\text { por la naturaleza del } \\
\text { paisaje y prefieren paseos }\end{array}$ \\
\hline Motivación & $62 \%$ paseos recreativos en familia & familiares al lugar una \\
\hline Frecuencia de visita & $60 \%$ visitan una vez al ańo & vez al año. \\
\hline
\end{tabular}

Fuente: Encuesta aplicada una muestra aleatoria de 100 visitantes en la localidad de Canta, con un margen de error de $\pm 5 \%$.

Lo que más se resalta de los resultados de la encuesta, es la preferencia de los visitantes que podrían arribar a Lachaqui, ya que más de las tres cuartas partes de los encuestados prefieren la naturaleza y visitas en grupos, particularidad que podría satisfacer el espacio rural de Lachaqui con sus recursos integrados, ya que la naturalidad del paisaje es uno de sus más grandes potenciales en el espacio en análisis. Esto refuerza la idea de la potencialidad del espacio rural para integrarse a un espacio turístico.

\subsection{Planta e infraestructura turística de Lachaqui}

Es uno de los aspectos del espacio rural de Lachaqui con mayor deficiencia. Dentro de este espacio no se han establecido aún algún establecimiento conformante de una adecuada planta turística, pues estos se encuentran dentro del área urbana pudiendo vincularse dentro de la dinámica de flujo de las visitas turísticas. Cabe resaltar que la 
planta turística se encuentra conformada por los establecimientos de hospedaje y de alimentación, tal cual se refleja en las Tablas 5 y 6.

Tabla 5. Caracterización de los establecimientos de hospedaje en Lachaqui

\begin{tabular}{|c|c|c|c|c|c|}
\hline \multirow{2}{*}{$\mathrm{N}^{\circ}$} & \multirow{2}{*}{$\begin{array}{l}\text { Nombre del } \\
\text { establecimiento }\end{array}$} & \multirow{2}{*}{ Tipo } & \multicolumn{3}{|c|}{ Servicios } \\
\hline & & & Alim & $\mathbf{T v}$ & Bar \\
\hline 1 & Escorpio & Hospedaje familiar & - & $\mathrm{X}$ & - \\
\hline 2 & Lachaqui & Hostal & - & $\mathrm{X}$ & - \\
\hline 3 & Hospedaje municipal & Hospedaje municipal & - & - & - \\
\hline
\end{tabular}

Fuente: Ficha de observación adaptada de Ricaurte, 2009.

Tabla 6. Caracterización de los establecimientos de alimentación en Lachaqui

\begin{tabular}{cllcc}
\hline $\mathbf{N}^{\circ}$ & $\begin{array}{l}\text { Nombre del } \\
\text { establecimiento }\end{array}$ & Tipo & Capacidad & Especialidad \\
\hline 1 & El Zurdo & Restaurant Bar & 20 & Variado \\
2 & Chapita & Restaurant & $\mathrm{s} / \mathrm{i}$ & Variado \\
3 & Purita Selva & Restaurant Bar & $\mathrm{s} / \mathrm{i}$ & Variado \\
\hline
\end{tabular}

Fuente: Ficha de observación adaptada de Ricaurte, 2009.

s/i: sin información

Cabe resaltar que los negocios surgidos en los últimos años respecto a la prestación de los servicios vinculados al turismo, y que forman parte de la planta turística, son casos de emprendimiento particular de personas y familias, ya que no forma parte de algún plan de desarrollo desde la gestión pública local. Su caracterización y desarrollo ha obedecido a situaciones pasajeras del turismo eventual característico de Lachaqui, así como su establecimiento, ya que, al no existir una zonificación urbana, y mucho menos un plan de ordenamiento territorial, los negocios de los servicios turísticos han surgido de forma espontánea obedeciendo a coyunturas temporales de la propia localidad.

La temporalidad de las visitas en Lachaqui ha ido determinando la dinámica de funcionalidad de los negocios turísticos, por ello en los meses de mayores visitas, como la semana de la festividad de Semana Santa (marzo, abril), de Fiestas Patrias (julio), o las semanas de fiestas locales (mayo, junio, entre otros) son los momentos de mayor demanda de servicios. En algunos momentos han surgido «negocios golondrinos» solo para cubrir esa demanda; sin embargo, lo mostrado en las tablas anteriores, obedecen a negocios permanentes, teniendo un mayor número de ventas y mejor rentabilidad en las temporadas mencionadas.

En el caso de la infraestructura, dentro del espacio rural de Lachaqui, se visualiza una rudimentaria infraestructura de acceso y de desplazamiento conformada por 
carreteras afirmadas y caminos de herradura que logran conectar los recursos turísticos ya descritos con el centro urbano, y, a su vez, pueden ser aprovechados para el paseo en bicicleta y moto, así como para la observación de la flora y fauna, realizar caminatas, tomar fotografías, entre otras actividades que puedan complementar la visita a este espacio. Esto podría fortalecer la interpretación ambiental del espacio y paisaje rural por parte de los visitantes. Debido a la ruralidad del espacio, que lo caracteriza como un espacio natural poco intervenido, es escasa la presencia de una infraestructura que facilite el tránsito de los visitantes. Por otro lado, la señalización es inexistente en estos caminos rurales; sin embargo, estos caminos tienen una utilidad consecuente por la población local que logra usarlo como medio de desplazamiento a sus linderos o espacios de producción, los cuales presentan un cambio de uso con la llegada de los visitantes. Uno de estos caminos es el que se observa en la Figura 3, que conecta el mirador del cerro de Champacra, el bosque de piedras y el rastro del inca con el centro urbano de Lachaqui; camino de herradura de unos seis kilómetros aproximadamente que en su recorrido con diferentes pendientes no solo permite conectar los recursos turísticos mencionados, sino que en el mismo recorrido se permite observar el característico paisaje del espacio rural del país, donde la producción agrícola y ganadera forma parte de este recorrido de unas tres a cuatro horas, dependiendo del estado físico del caminante o las actividades que uno puede desarrollar alternadamente.

Figura 3. Mapa de ruta turística de Lachaqui en Google Earth

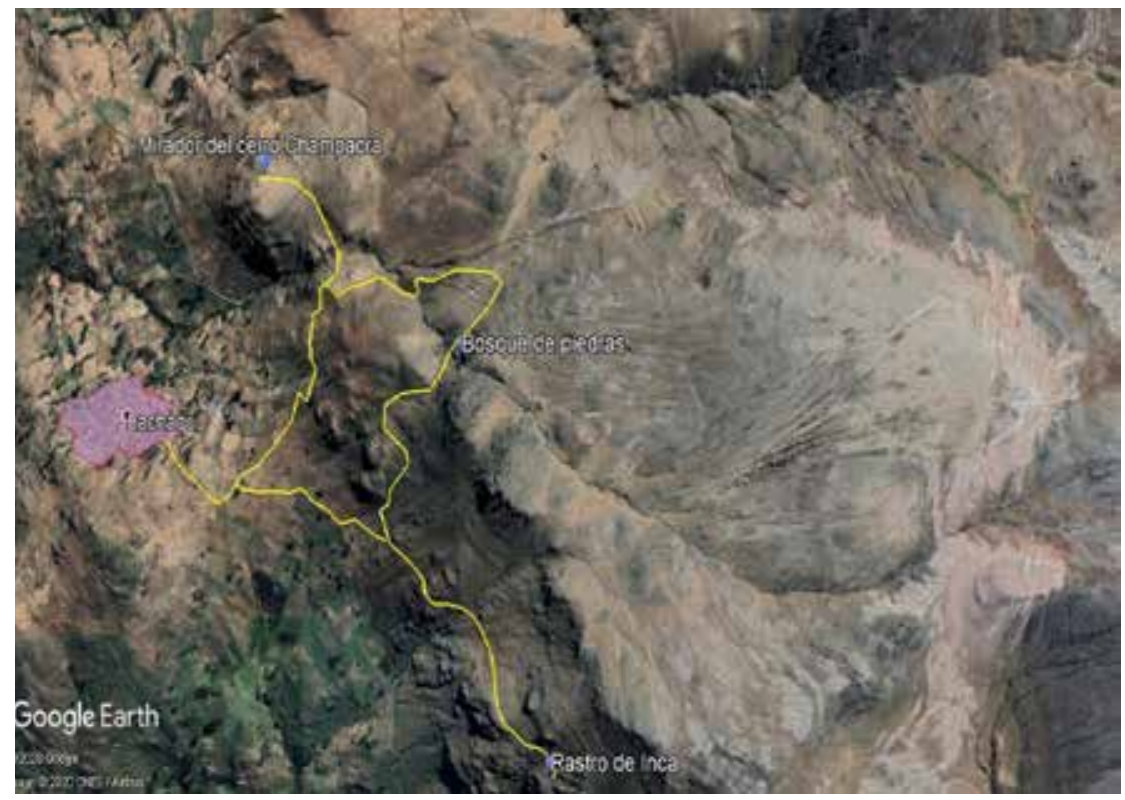

Elaboración propia, 2019. 


\subsection{Gobernanza de Lachaqui}

La gobernanza en el espacio rural de Lachaqui se encuentra conformada por las acciones de la gestión del turismo por parte de la municipalidad local, instituciones de interés y la comunidad campesina. De acuerdo con la información brindada por una funcionaria pública de la municipalidad distrital, el turismo no es una actividad de interés absoluto, debido a que existen necesidades locales más inmediatas que deben ser atendidas por la gestión municipal, como el cierre de brechas en la salud, educación e infraestructura. Las actividades económicas de mayor dinámica por la comunidad y población local son la ganadería y la agricultura, por lo que la gestión municipal también está dirigida hacia la satisfacción de necesidades inmediatas y no inmediatas. Sin embargo, desde hace unos años, debido a factores externos, como el mejoramiento en la carretera de acceso a la provincia de Canta, la coyuntura económica nacional y el crecimiento demográfico de la ciudad de Lima, se ha ido incrementando las visitas a la localidad de Canta y Lachaqui, sobre todo en temporada de alta demanda, por lo que la mirada al turismo por parte de la gestión municipal ha cobrado un interés particular, por ello en la última gestión (2014-2018) se han realizado esfuerzos en miras de una planificación turística. En concreto, se ha venido realizando el inventario de recursos turísticos y la elaboración del Plan de Desarrollo Turístico Local (PDTL) dentro de las metas del Ministerio de Economía y Finanzas (MEF), denominado «Meta 38». Estos dos hechos concretos brindan luces de una atención de la gestión pública local al turismo.

Por otro lado, de acuerdo con lo dialogado con representantes de la comunidad campesina de Lachaqui, existe también un interés por participar en la dinámica propia del turismo. Sin embargo, las capacidades para este rubro son limitadas, tal como lo manifiesta el informante clave quien sostiene que en la zona hace falta gente capacitada. Estas capacidades están relacionadas a temas como las buenas prácticas de atención al cliente, ideas en formar nuevas ideas de negocios. La comunidad campesina es un órgano de gestión local cuya estructura funcional permitiría el desarrollo de capacitaciones mediante acciones conjuntas con la municipalidad en convenio con instituciones del Estado o la academia. Un importante potencial es la cordialidad que existe entre la comunidad campesina con la municipalidad. Es importante que este puente de cordialidad se conserve y se concrete en actividades conjuntas como el desarrollo de capacidades tal como manifiestan los miembros de la comunidad campesina. 
Figura 4. Componentes de la gobernanza turística en Lachaqui


\subsection{Potencialidad que presenta el espacio rural del distrito de Lachaqui para el desarrollo del turismo}

El análisis de la potencialidad del turismo en el espacio rural de Lachaqui, para fines de la presente investigación, pasa por una descripción y análisis de los componentes del sistema turístico en el espacio rural, tal cual se ha realizado en las líneas anteriores. Luego, tomando como base la matriz de potencialidad turística de Sandoval (2006), se procede a determinar el nivel de potencialidad de los recursos turísticos y del espacio rural en su conjunto. Los recursos turísticos identificados en el espacio rural de Lachaqui, de manera íntegra juegan un rol dinamizador dentro del espacio rural, pues vendría a conformar la motivación de las visitas, por ello la determinación de su potencialidad contribuirá a la gestión local para reflexionar sobre la inversión que en ella pueden darse. En la Tabla 7 se determina los recursos turísticos con el nivel de su potencialidad.

Se observa que, de los nueve recursos turísticos identificados, cinco presentan un alto potencial (AP) y cuatro mediando potencial (MP), por lo que, al no tener todos los recursos turísticos un alto potencial para el turismo dentro de este espacio rural podría llevar a la conjetura de que el turismo no encuentra en este espacio una fortaleza que podría generar una importante dinámica en las visitas. Se observa, además, que los factores que influyen en la categorización de mediana potencialidad de algunos recursos son las pocas posibilidades de desarrollo de actividades de turismo rural comunitario, poca presencia de atractivos para el turismo rural comunitario y limitada posibilidad de observar paisaje rural se resalta que esto es para el caso de los recursos con mediana potencialidad. A nivel del espacio rural de Lachaqui, su potencialidad se determina en la Tabla 8. 
Tabla 7. Determinación del nivel de potencialidad de los recursos turísticos del espacio rural de Lachaqui

\begin{tabular}{|c|c|c|c|c|c|c|c|c|c|}
\hline \multirow{2}{*}{$\begin{array}{l}\text { Indicadores de } \\
\text { potencialidad }\end{array}$} & \multicolumn{9}{|c|}{ Recursos turísticos del espacio rural de Lachaqui } \\
\hline & SJVL & CAQL & PAHL & PPVL & PSLL & MCChL & MCCL & $\mathrm{BPL}$ & RIL \\
\hline $\begin{array}{l}\text { Cercanía a centros } \\
\text { urbanos importantes }\end{array}$ & 3 & 2 & 2 & 1 & 2 & 3 & 3 & 3 & 3 \\
\hline $\begin{array}{l}\text { Características del } \\
\text { trayecto hacía el área }\end{array}$ & 2 & 1 & 1 & 3 & 2 & 2 & 2 & 2 & 1 \\
\hline $\begin{array}{l}\text { Posibilidades } \\
\text { de desarrollo de } \\
\text { actividades de turismo } \\
\text { rural comunitario }\end{array}$ & 2 & 1 & 1 & 1 & 1 & 3 & 3 & 3 & 3 \\
\hline $\begin{array}{l}\text { Presencia de atractivos } \\
\text { para el turismo rural } \\
\text { comunitario }\end{array}$ & 3 & 1 & 1 & 1 & 1 & 3 & 3 & 3 & 3 \\
\hline $\begin{array}{l}\text { Posibilidad de } \\
\text { observar paisaje rural }\end{array}$ & 3 & 1 & 1 & 1 & 1 & 3 & 3 & 3 & 3 \\
\hline $\begin{array}{l}\text { Características de } \\
\text { interés turístico }\end{array}$ & 2 & 3 & 3 & 2 & 1 & 3 & 3 & 3 & 2 \\
\hline $\begin{array}{l}\text { Lugares de interés } \\
\text { cultural }\end{array}$ & 2 & 2 & 2 & 1 & 1 & 2 & 2 & 2 & 2 \\
\hline $\begin{array}{l}\text { Las características } \\
\text { intrínsecas del área } \\
\text { son: }\end{array}$ & 2 & 1 & 1 & 2 & 2 & 2 & 2 & 2 & 2 \\
\hline $\begin{array}{l}\text { Potencialidad escénica } \\
\text { de los alrededores del } \\
\text { área }\end{array}$ & 3 & 2 & 2 & 3 & 2 & 3 & 3 & 3 & 3 \\
\hline $\begin{array}{l}\text { Potencial para } \\
\text { integrar el área a } \\
\text { circuitos de interés } \\
\text { turístico }\end{array}$ & 3 & 2 & 2 & 1 & 2 & 3 & 3 & 3 & 3 \\
\hline $\begin{array}{l}\text { Suma de evaluación } \\
\text { de potencialidad }\end{array}$ & 25 & 16 & 16 & 16 & 15 & 27 & 27 & 27 & 25 \\
\hline Escala de valoración & $\mathrm{AP}$ & MP & MP & MP & MP & $\mathrm{AP}$ & $\mathrm{AP}$ & $\mathrm{AP}$ & AP \\
\hline
\end{tabular}

Fuente: Informe de inventario de recursos turísticos de la Municipalidad Distrital de Lachaqui, 2018. 
Tabla 8. Determinación del nivel de potencialidad del espacio rural de Lachaqui

\begin{tabular}{lc}
\hline \multicolumn{1}{c}{ Indicadores de potencialidad } & Espacio rural de Lachaqui \\
\hline Cercanía a centros urbanos importantes & 2 \\
Características del trayecto hacía el área & 2 \\
Posibilidades de desarrollo de actividades de turismo rural & 3 \\
comunitario & 3 \\
Presencia de atractivos para el turismo rural comunitario & 3 \\
Posibilidad de observar paisaje rural & 2 \\
Características de interés turístico & 2 \\
Lugares de interés cultural & 2 \\
Las características intrínsecas del área son: & 3 \\
Potencialidad escénica de los alrededores del área & 2 \\
Potencial para integrar el área a circuitos de interés turístico & 24 \\
Suma de evaluación de potencialidad & MP \\
Escala de valoración & 24 \\
\hline
\end{tabular}

Fuente: Informe de inventario de recursos turísticos de la Municipalidad Distrital de Lachaqui, 2018.

Si bien en el espacio rural de Lachaqui la singularidad reside en el paisaje observable, y en las posibilidades de actividades de turismo rural como agroturismo, turismo de aventura y otros, existen aún deficiencias y limitaciones que impiden integrarlo en un área a circuitos turísticos, la infraestructura de accesibilidad y movilidad juega aquí un rol importante. Además, el estado de sus centros arqueológicos y la limitada participación de la comunidad local como parte de la gobernanza turística limitan la configuración del área con un auténtico atractivo de interés cultural. Todo ello de alguna manera permite justificar la categorización del espacio rural de Lachaqui con una mediana potencialidad turística.

Los resultados del estudio permiten mostrar de forma objetiva la situación del turismo no solo en el espacio rural de Lachaqui, sino además de la situación de esta actividad en cada espacio rural de nuestro país, donde pueden presentar una diversidad de recursos turísticos sin ser estos turísticos. En principio lo «turístico» lo determina el turista o visitante cuando se desplaza en un entorno no habitual para él, por lo que los recursos identificados nos dan una primera aproximación que estos recursos turísticos no son aún turísticos, pero presentan una potencialidad diferenciada para serlo. El estudio tomó como base el procedimiento del inventario de recursos turísticos del Mincetur (2012), pues esta actividad es una primera tarea para identificar, caracterizar y analizar la «idoneidad turística» de los recursos, que tienen una naturaleza primigenia alejada de la funcionalidad turística, pues es la necesidad de insertarse al mercado y generar rentabilidad para el cierre de brechas sociales por parte de la gobernanza turística local, 
la que ha generado que los espacios con funcionalidad histórica, cultural o aquellos que son resultado de procesos naturales con temporalidad geológica, sean insertados con una mirada turística y por ende su catalogación de recursos turísticos. Esto concuerda con lo realizado por Bassan y Cravero (2013), pues el inventario de estos recursos es la primera etapa en el análisis de los recursos para ser considerados turísticos.

Los espacios rurales son producto de la interacción de procesos naturales y sociales, donde el segundo moldea o configura al primero adaptándolo a las necesidades sociales sin resquebrajar o alterar significativamente el paisaje natural. De estos resulta el paisaje rural, con escenarios y recursos potenciales como ya descrito en líneas anteriores. Sin embargo, el establecimiento rural está determinado por las relaciones sociales comunales que dentro de ese espacio se ha ido configurando en las últimas décadas. Estas relaciones sociales, dentro de Lachaqui, se encuentra representado por la comunidad campesina y de todos sus miembros y no miembros dentro del mismo distrito. Estas relaciones sociales se manifiestan en el desarrollo de la ganadería, agricultura y las diversas fiestas —religiosas y no religiosas - que cada año se desenvuelve en ese espacio, fiestas que no tienen una dirección orientada al turista. No obstante, la particularidad de estos, la naturalidad de su praxis y la organización detrás de ello, cada vez, tiene aquella funcionalidad dentro de esta dinámica que se relaciona con la dinámica económica de los establecimientos de servicios conformantes de la planta turística. Al no tener una direccionalidad turística de estas actividades mencionadas, se correría peligro si se le dirigiera al mercado turístico, pues caería en el peligro de perder esa naturalidad y particularidad que la distingue, por ello dentro de la planificación del turismo local y rural, debe considerarse como una variable inalienable la territorialidad del espacio rural de Lachaqui, pues son estas relaciones sociales no turísticas que han fortalecido el territorio de este espacio, tal como lo sostienen Sánchez y Propin (2005), pues cuando el turismo se enfoca desde el territorio dentro de ese espacio, se puede sufrir escenarios de una teatralización del espacio natural y rural (Hernández, 2017) solo para la satisfacción del visitante, hecho que degrada la sostenibilidad, aspecto que se busca evitar dentro de la praxis del turismo rural en estos tiempos.

Mikery y Pérez (2014) en su trabajo de investigación nos describen las diversas tipologías de actividades que se practican dentro del espacio rural, como ecoturismo, agroturismo y el turismo rural comunitario, actividades que dentro del espacio rural de Lachaqui se presenta potencialidad para el desarrollo de estas, cabe recalcar que la gobernanza y la infraestructura turística son clave para ello, así como las capacidades que los individuos locales deben prestar atención a la hora de orientar o atender a los visitantes. Para mantener la sostenibilidad de la cuestión, es importante la comprensión de que no se debe llegar a la prevalencia y satisfacción del visitante sobre las necesidades locales, pues son estos turistas y visitantes que acuden a estos espacios en su leisure time (Boniface y Cooper, 2005), mientras que los individuos locales se encuentran 
en su work time, situación de contraste entre estos tiempos del tejido social de cada grupo, y que debe prestarse atención en la planificación y ordenamiento del territorio destinado al turismo. De esta afirmación, se resalta que la planificación del turismo debe realizarse dentro del esquema de la sostenibilidad, donde las necesidades locales y la conservación del paisaje natural deben ser acciones prioritarias sobre la rentabilidad económica particular o la satisfacción frívola del visitante, casos al respecto ocurren y han ocurrido en distintos puntos del país y del planeta, en los que los espacios turísticos han perdido esta categorización por sobreponer la rentabilidad sobre la sostenibilidad.

Por lo tanto, ante la afirmación de Covarrubias (2014) quien sostiene que «el potencial turístico lo determina la forma en que la oferta de productos y servicios turísticos de una localidad se adapta para satisfacer las necesidades actuales de esparcimiento y recreación de los turistas nacionales e internacionales». Se debe tener bastante cuidado a la hora de planificar el turismo en un espacio sobre todo si tiene carácter rural, pues, en un primer momento, el espacio se estructura de acuerdo a las necesidades de la población local, y, luego, de acuerdo a las necesidades de la misma población para poder dinamizar el turismo dentro de ese espacio. Por lo que, en una primera aproximación para realizar el estudio del potencial de un espacio, es válido lo afirmado por el autor. Sin embargo, cuando la población local ha interiorizado la necesidad del turismo como actividad motora, se debe planificar las acciones con miras de la sostenibilidad de la población local y la naturaleza del entorno, y debe ir más allá de lo planteado por el mismo autor, sino estaríamos recayendo en una situación de una construcción artificial del espacio sólo en miras de la necesidad del visitante, pues si éste no arribaría, lo construido artificialmente quedaría exiguo a una necesidad colectiva local y a una banalidad de las posibles inversiones públicas y/o privadas.

\section{Conclusión}

El estudio concluye sosteniendo que el espacio rural de Lachaqui presenta una mediana o regular potencialidad turística, ello debido a que aún falta integrar algunos factores que dinamizan el sistema turístico dentro de dicho espacio. Se sostiene que la singularidad en el área de estudio reside en el paisaje rural observable y en las posibilidades de actividades de turismo rural como agroturismo, turismo de aventura y otros. Pese a ello, existen aún deficiencias y limitaciones que impiden integrarlo en un área a circuitos turísticos, la infraestructura de accesibilidad y movilidad comprende un rol importante. Además, el estado de sus centros arqueológicos y la limitada participación de la comunidad local como parte de la gobernanza turística limitan la configuración del área con un auténtico atractivo de interés rural y/o cultural. Todo ello de alguna manera permite justificar la categorización del espacio rural de Lachaqui con una mediana potencialidad turística. 
Por otro lado, los recursos turísticos en Lachaqui son diversos, ello depende de la mirada analítica; sin embargo, dentro del espacio rural se han identificado nueve recursos, con diferentes niveles de potencialidad. La integración y vinculación con actividades de turismo rural comunitario lograría prevalecer la potencialidad del espacio al mercado turístico. Pero todo ello se vería limitado si la infraestructura, que es deficiente aún, y la planta turística que también es limitada en aspectos de capacidades, no se plantean alternativas de mejora continua a la llegada de olas turísticas como acontece en estos tiempos. Esta posible ola turística en el espacio rural de Lachaqui estaría conformado por una ola de visitantes limeños, predominantemente jóvenes, solteros universitarios, dependientes y activos laboralmente, con ingresos mensuales menores a los mil soles, utilizan el transporte público, internet y periódico, motivados por la naturaleza del paisaje y prefieren paseos familiares al lugar una vez al año.

Ante ello, el papel que juega la gobernanza, que en la actualidad no vislumbran al turismo como actividad motriz de actividades económicas, es trascendental, ya que la gestión del turismo debe tener un largo alcance en plazos y tiempos, por ello urge la necesidad de planificar la actividad de acuerdo a las características y dinámicas territoriales, sin desligarse de su patrón natural y cultural, bases para la sostenibilidad del turismo.

\section{REFERENCIAS}

Bassan, C. y Cravero, S. (2013). Relevamiento del Patrimonio Turístico del Partido de Pinamar. Universidad Argentina de la Empresa.

Boniface, B. y Cooper, C, (2005). Worldwide destinations casebook. The geography of travel and tourism. Ed. Elsevier Butterworth-Heinemann, Italy.

Boullón, R. (2006). Planificación del espacio turístico (Cuarta ed.). México: Trillas.

Calame, M. (2010). Espacio rural pequeñas y medianas colectividades y gobernanza mundial. Editorial Cuadernos de Propuesta, Francia.

Covarrubias, R. (2014). Evaluación del potencial en municipios turísticos a través de metodologias participativas. México: Eumed.

Delgado, O. (2001). Espacio y territorios. Razón, pasión e imaginarios. Bogotá: Universidad Nacional de Colombia.

Díaz, I., Nava, M., Gallardo, F., García, J. y Fajersson, P. (2008). Potencial para turismo alternativo del municipio de Paso de Ovejas, Veracruz. Tropical and Subtropical Agroecosystems, (8), 199-208.

García, M., Tullas, A. y Valdovinos, N. (1995). Geografía rural. Barcelona: Editorial Síntesis. Harvey, D. (2007). Espacios del capital hacia una geografía crítica. Madrid: Ediciones Akal. 
Hernández, F. (2017). El mundo es ancho y turístico. Apuntes teórico-metodológicos para una geografía del turismo en la actualidad. Espacio y Desarrollo, (29), 57-90

Hernández R., Fernández C. y Baptista P. (2014). Metodología de la investigación (sexta ed.). México: McGraw-Hill/Interamericana Editores.

Lefebvre, H. (1974). La production de l'espace. París: Éditions Anthropos.

Merinero, R. y Zamora, E. (2009). La colaboración entre los actores turísticos en ciudades patrimoniales. Reflexiones para el análisis del desarrollo turístico. PASOS. Revista de Turismo y Patrimonio Cultural, 7(2), 219-238.

Mikery, M. y Pérez, A. (2014). Métodos para el análisis del potencial turístico del territorio rural. Revista Mexicana de Ciencias Agricolas, (9), 1729-1740.

Ministerio de Comercio Exterior y Turismo - Mincetur. (2012). Manual para la Formulación del Inventario de Recursos Turísticos a Nivel Nacional. Lima.

Mora, C. (2010). Turismo y planificación: Diagnóstico turístico del Municipio de Victoria, Entre Rios. Una mirada del presente, un aporte a su futuro. Buenos Aires: Universidad Abierta Interamericana de Buenos Aires.

Ñaupas, H., Mejía, E., Novoa, E. y Villagómez, A. (2014). Metodología de la investigación. Cuantitativa - cualitativa y redacción de tesis (Cuarta ed.). Bogotá: Ediciones de la U.

Pariente, E., Chávez, J y Reynel, C. (2016). Evaluación del potencial turístico del distrito de Huarango - San Ignacio, Cajamarca-Perú. Ecología Aplicada, 15(1), 37-46.

Posada, M. (1999). El espacio rural entre la producción y el consumo: algunas referencias para el caso argentino. Eure, (25), 63-76.

Ramírez, B. y López, L. (2015). Espacio, paisaje, región, territorio y lugar: la diversidad en el pensamiento contemporáneo. México: UNAM.

Real Academia Española (2018). Rural [online]. Diccionario de la lengua española. Recuperado de http://dle.rae.es/?id=WqzJ2ZS

Ricaurte, C. (2009). Manual para el diagnóstico turístico local. Guía para planificadores. Guayaquil: Escuela Superior Politécnica del Litoral.

Rojas, T. (2005). Epistemología de la Geografía...una aproximación para entender esta disciplina. Terra Nueva Etapa, XXI(30), 141-162.

Sandoval, E. (2006). Ecoturismo: operación técnica y gestión ambiental. México: Trillas.

Santos, M. (1996). Metamorfosis del espacio habitado. Barcelona: Oikos-Tau

Sánchez, Á. y Propin, E. (2005). Potencial regional del turismo en la zona metropolitana de Tampico, México. Cuadernos Geográficos, (37), 153-182

Soria, E. (2014). Proyección del Modelo FUZZY-SECTUR para evaluar el potencial turístico de un territorio. Retos Turísticos, (13), 1-13.

Vargas, G. (2012). Espacio y territorio en el análisis geográfico. México: Redalyc.

Zimmer, P. y Grassmann, S. (1996). Evaluar el potencial turistico de un territorio. Extremadura: Liaison Entre Actions de Développement de l'économie Rurale, Observatoire Européen Leader. 